CLINICAL STUDY

\title{
Extended family history of autoimmune diseases and phenotype and genotype of children with newly diagnosed type 1 diabetes
}

\author{
Anna Parkkola ${ }^{1}$, Taina Härkönen ${ }^{1}$, Samppa J Ryhänen ${ }^{1}$, Jorma Ilonen ${ }^{2,3}$, Mikael Knip ${ }^{1,4,5}$ and \\ Finnish Pediatric Diabetes Register ${ }^{\dagger}$ \\ ${ }^{1}$ Children's Hospital, University of Helsinki and Helsinki University Central Hospital, PO Box 22, FI-O0014 Helsinki, Finland, ${ }^{2}$ Immunogenetics \\ Laboratory, University of Turku, FI-20520 Turku, Finland, ${ }^{3}$ Department of Clinical Microbiology, University of Eastern Finland, FI-70210 Kuopio, \\ Finland, ${ }^{4}$ Folkhälsan Research Center, FI-O0290 Helsinki, Finland and ${ }^{5}$ Department of Pediatrics, Tampere University Hospital, FI-33520 Tampere, \\ Finland \\ (Correspondence should be addressed to M Knip at Children's Hospital, University of Helsinki and Helsinki University Central Hospital; \\ Email: mikael.knip@helsinki.fi) \\ $\dagger^{\dagger}$ (Investigators are listed in the Acknowledgements section)
}

\begin{abstract}
Objective: Based on the concept of clustering autoimmunity, children with a positive family history of autoimmunity could be expected to have a different pathogenetic form of type 1 diabetes (T1D) and thus a stronger autoimmune reactivity against $\beta$-cells and an increased prevalence of the HLA-DR3-DQ2 haplotype.

Design and methods: We tested this hypothesis in a cross-sectional observational study from the Finnish Pediatric Diabetes Register. HLA class II genotypes and $\beta$-cell autoantibodies were analyzed, and data on the extended family history of autoimmunity and clinical markers at diagnosis were collected with a structured questionnaire from 1488 children diagnosed with T1D under the age of 15 years (57\% males).

Results: Only 23 children (1.5\%) had another autoimmune disease (AID) known at diagnosis, and they had a milder metabolic decompensation at diabetes presentation. One-third (31.4\%) had at least one relative with an AID other than T1D with affected mothers being overrepresented $(8.2 \%)$ compared with fathers $(2.8 \%)$. The children with a positive family history of other AIDs had higher levels of islet cell antibodies $(P=0.003)$, and the HLA-DR3-DQ2 haplotype in the children was associated with celiac disease in the extended family $(P<0.001)$, but not with an increased frequency of autoimmune disorders, in general.

Conclusions: Approximately one-third of children with newly diagnosed T1D have a first- and/or second-degree relative affected by an AID. Our data do not consistently support the hypothesis of differential pathogenetic mechanisms in such children.
\end{abstract}

European Journal of Endocrinology 169 171-178

\section{Introduction}

Autoimmunity clusters in individuals and in families are due to largely unknown genetic and environmental factors. Type 1 diabetes (T1D) is associated with other autoimmune disorders such as autoimmune thyroiditis (AIT) $(1,2,3,4,5)$, celiac disease $(\mathrm{CD})(1,3,4,5)$, Addison's disease $(2,4,5)$, pernicious anemia $(4,5)$, rheumatoid arthritis $(1,4)$, and multiple sclerosis $(6,7)$. Increased risk of multiple autoimmune manifestations already exists at T1D diagnosis, but it increases significantly with follow-up (8, 9). At diagnosis, 9-19\% of the children with T1D have another autoimmune disease (AID) based on autoantibody screening $(8,10)$; $\mathrm{CD}(1.5-3.3 \%)(10,11,12,13)$ and AIT $(0.6-3.1 \%)(10,13,14)$ are the most common conditions. Relatives of patients are at a greater risk of AIDs with AIT, CD, and rheumatoid arthritis as the most common conditions $(1,3,8,15,16,17,18)$.

The HLA class II haplotypes DRB1*0401/2/4/ 5-DQA1*0301-DQB1*0302(DR4-DQ8) and (DRB1*03)$D Q A 1 * 05-D Q B 1 * 02$ (DR3-DQ2) are the major contributors to the genetic risk of T1D among Caucasians, and the latter also strongly predisposes to $\mathrm{CD}$ and other AIDs $(11,19,20,21,22,23,24,25)$. Among the T1Drelated autoantibodies, glutamic acid decarboxylase autoantibodies (GADAs) have been directly associated with $(14,20,22,26)$ and antibodies to the islet antigen 2 protein (IA-2A) have been inversely associated (20) with the risk of other AIDs.

Studies evaluating the frequency of other AIDs in the extended family from the time of diagnosis of T1D are scarce, and the effects of a positive family history of AIDs on the phenotype and genotype of newly diagnosed 
children are largely unknown. We, therefore, set out to characterize the effects of a positive history of other AIDs in the extended family on metabolic, immunological, and genetic markers in children with newly diagnosed T1D. We hypothesized that the increased burden of autoimmunity would lead to a pathogenetically distinct subset of T1D in children with a positive family history of other AIDs. These children were expected to have an increased prevalence of the DR3-DQ2 haplotype and a stronger reactivity against $\beta$-cell antigens, reflected by more frequent autoantibodies and higher titers.

\section{Subjects and methods}

\section{Study design and subjects}

The nationwide Finnish Pediatric Diabetes Register (27) has covered more than $90 \%$ of children diagnosed with T1D since June 2002 (28). By April 2007, the register had covered 1544 children who had T1D-related autoantibodies analyzed and were diagnosed with T1D before the age of 15 years. Children with no information on their relatives in the register and one child with a known insulin gene mutation were excluded. Only one child from each family was included as the index case. Thus, the study cohort comprised 1488 children with a median age of 8.23 years (range $0.28-14.99$ years) at diagnosis, and the proportion of boys was $56.9 \%$. Serum samples were obtained at a median of 5 days after diagnosis.

The register contains information on the family history of AIDs collected by a structured questionnaire (29). The families are asked to list any family members with AIDs, and the following examples are given: CD, dermatitis herpetiformis, AIT, autoimmune adrenal dysfunction, rheumatoid arthritis, multiple sclerosis, pernicious anemia, and systemic lupus erythematosus. They are asked about the total number of first-degree relatives (parents and siblings), but not about that of second-degree relatives (grandparents and siblings of parents). The register does not include follow-up of the families after the diagnosis.

Approximately $70 \%$ of the families participating in the register also provided blood samples for the Biobank. T1Drelated autoantibodies (islet cell antibodies (ICAs), insulin autoantibodies (IAAs), GADA, and IA-2A) and HLA$D R-D Q A 1-D Q B 1$ haplotypes (30) were analyzed. Legal guardians and every subject aged 18 years or above gave written informed consent. Participants aged 10-17 years gave written assent. The Ethics Committee of the Hospital District of Helsinki and Uusimaa approved the protocol.

For the analysis, different groupings were applied. First, the children with a known additional AID already at diagnosis were compared with those with T1D only. Second, a few descriptions of a positive family history of AIDs were used: the children with first- and/or second-degree relatives (extended family) with AID diagnoses, the children with a positive extended family history specifically of AIT (hypo/hyperthyroidism), CD (CD, dermatitis herpetiformis), or rheumatoid diseases (e.g. rheumatoid arthritis and systemic lupus erythematosus, Sjögren's syndrome, ankylosing spondylitis, mixed connective tissue disease, and scleroderma), and the children belonging to the so-called autoimmune families (extended families with greater than three AID diagnoses (different diseases and/or family members, e.g. two persons both of whom have T1D and CD) and/or greater than two different AIDs including diagnoses of the index child). These groups were then compared with children with no family history of T1D or any other AIDs.

To allow the observation of the effects of a positive family history of only AIDs other than T1D, children with a positive family history of T1D were excluded from the analysis, except when defining autoimmune families and analyzing index children with an additional AID or T1D only. The families who did not provide any information on AIDs of any family members (10/1488) were counted as not having any family members affected by AIDs. For the rest of the families, we included all the provided information in the analysis even when the information on the extended family was incomplete.

\section{Autoantibody assays}

IAA, GADA, and IA-2A levels were quantified with specific radiobinding assays $(31,32,33)$ with cutoff limits of 2.80, 5.36, and 0.77 relative units (RU) respectively. The limits for positivity were based on the 99th percentiles in more than 350 Finnish control children. In the 2009 Diabetes Autoantibody Standardization Program (DASP), these assays exhibited sensitivities of 42,78 , and $64 \%$ and specificities of 99,95 , and $99 \%$ respectively. ICAs were analyzed with indirect immunofluorescense using human group 0 donor pancreas and expressed in Juvenile Diabetes Foundation (JDF) units with 2.5 JDF units as the detection limit (34). We included only results at or above the cutoffs for the calculation of median titers.

\section{HLA genotyping}

We used a PCR-based lanthanide-labeled hybridization method using time-resolved fluorometry for the detection of the major T1D risk-associated DR-DQ haplotypes (30). The number of children with HLA typing available was $1454(97.7 \%)$.

\section{Markers of metabolic decompensation}

Local laboratories analyzed plasma glucose and $\beta$-hydroxybutyrate levels and $\mathrm{pH}$ at diagnosis. Data on plasma glucose levels were missing in 19 subjects $(1.3 \%)$, on $\mathrm{pH}$ in 35 subjects $(2.4 \%)$, and on $\beta$-hydroxybutyrate in 284 subjects (19.1\%). Owing to 


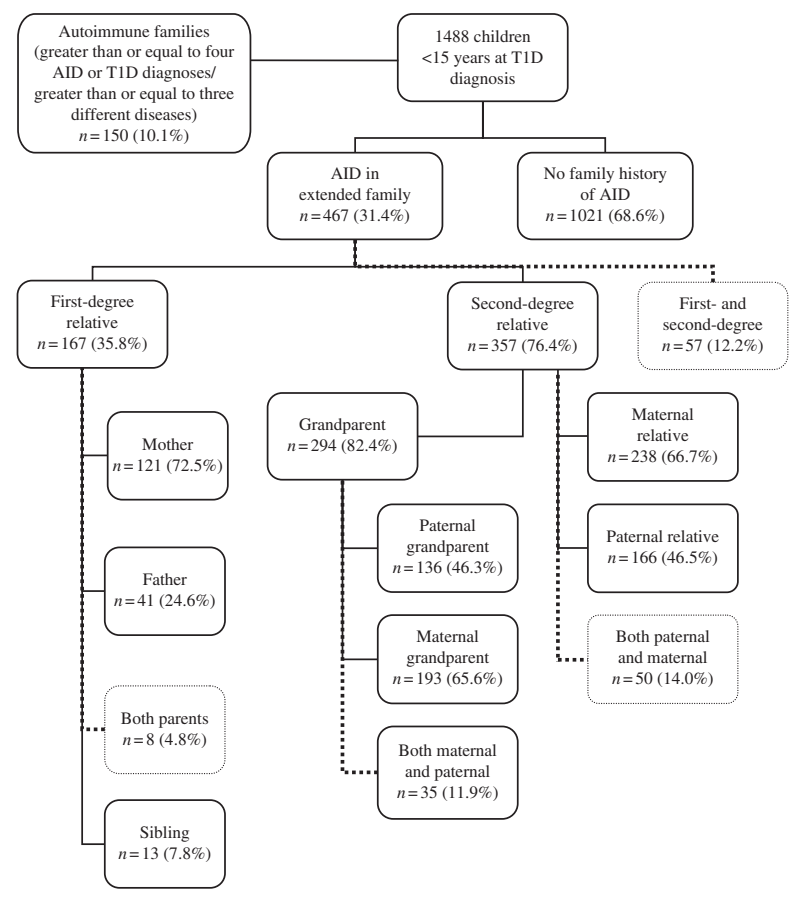

Figure 1 Grouping of the index cases according to who in the extended family is affected by AIDs. The dashed lines indicate cases with affected relatives from more than one category of relatives. These cases are also included in the total number of each category of relatives. AID, autoimmune disease (other than T1D); T1D, type 1 diabetes.

a lack of nationwide standardization, HbAlc measurements were not recorded.

\section{Statistical analysis}

IBM SPSS 19 statistical software package and R 12.2.1 package for statistical computing (35) were used for the analysis. For the comparison of frequencies, crosstabulation, $\chi^{2}$-statistics, and Fisher's exact test were used. Continuous variables with a normal distribution were analyzed with Student's $t$-test and those with a skewed distribution with Mann-Whitney U test/Wilcoxon's rank sum test. Logistic regression and quantile regression in $R$ (quantreg 4.54) were used when adjusting for confounding factors. A two-tailed $P$ value of $<0.05$ was considered statistically significant. Bonferroni's correction for multiple comparisons was not applied due to its overly conservative nature. Multiplicity issues were taken into account in cautious interpretation of the results.

\section{Results}

\section{History of AIDs}

The number of children with another AID already known at T1D diagnosis was $23(1.5 \%)$; CD was the most common condition (10/23), followed by AIT
(9/23), rheumatoid arthritis (4/23), and colitis ulcerosa (1/23). One child had both AIT and rheumatoid arthritis. Considering the family history of AIDs, a total of 467 index children $(31.4 \%)$ had at least one extended family member with an AID other than T1D (Fig. 1). At least one affected first-degree relative was reported by $167(11.2 \%)$ cases and an affected seconddegree relative by 357 cases $(24.0 \%)$ and 57 cases $(3.8 \%)$ had both. More children had an affected mother $(8.1 \%)$ than an affected father $(2.8 \% ; P<0.001)$, and $13.0 \%$ of the children had an affected maternal grandparent and $9.1 \%$ had an affected paternal grandparent $(P<0.001)$. An affected maternal relative was reported by $16.0 \%$ of the cases and an affected paternal relative by $11.2 \%(P<0.001)$. The number of index cases with an affected sibling was $13(0.9 \%)$, which is $1.1 \%$ of those 1200 index cases who had siblings. The prevalence of an AID other than T1D was $0.7 \%$ among all the siblings $(14 / 2087)$ and $5.8 \%$ among the grandparents (343/5952).

The number of autoimmune diagnoses in the extended family, including diseases of the index child and T1D, varied between 1 and 13 and the number of different AIDs varied between 1 and 5. When T1D was excluded, the figures were $0-8$ and $0-4$ respectively. According to these data, $150(10.1 \%)$ subjects fulfilled our criteria for an autoimmune family (Fig. 1). AIT in the extended family was reported by $17.0 \%$ of the families, rheumatoid disease by $12.0 \%$, CD by $5.2 \%$, and other AIDs by $3.5 \%$. These diseases were more frequently reported in second-degree relatives than in first-degree ones (Fig. 2).

The sex distribution and the age at diagnosis of the index cases were similar in the groups of comparison, although the children with a known additional AID tended to be older (Table 1). The children with relatives affected by an AID came, in general, from larger

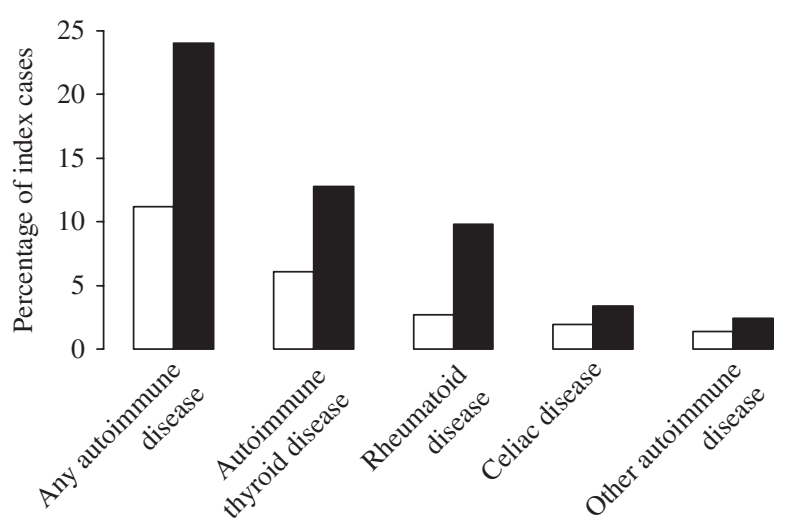

Figure 2 Proportions of children with newly diagnosed type 1 diabetes (T1D) with first- or second-degree relatives affected by autoimmune diseases other than T1D (white bars indicate firstdegree relatives and black bars indicate second-degree relatives). 
Table 1 Metabolic, immunological, and genetic markers in the children with another known autoimmune disease (AID) in addition to type 1 diabetes (T1D) and children with T1D only. Bold P values refer to significant differences.

\begin{tabular}{|c|c|c|c|c|}
\hline & $\begin{array}{c}\text { Children with } \\
\text { additional AIDs }(n=23)\end{array}$ & $\begin{array}{l}\text { Children with T1D } \\
\text { only }(n=1465)\end{array}$ & $\begin{array}{l}\text { Unadjusted } \\
P \text { value }\end{array}$ & $\begin{array}{l}\text { Adjusted } \\
P \text { value }^{\mathrm{a}}\end{array}$ \\
\hline \multicolumn{5}{|l|}{ Demographics } \\
\hline Sex: male (\%) & 43.5 & 57.1 & 0.21 & \\
\hline Age at diagnosis (years), median (range) & $9.5(4.3-14.99)$ & $8.2(0.28-14.98)$ & 0.06 & \\
\hline Number of children in the family, median (mean) & $2(2.61)$ & $2(2.40)$ & 0.88 & \\
\hline Positive extended family history of T1D (\%) & 21.7 & 21.8 & 1.00 & \\
\hline \multicolumn{5}{|l|}{ Metabolic decompensation at diagnosis } \\
\hline Plasma glucose $(\mathrm{mmol} / \mathrm{l})$, median (range) & $18.6(6.0-41.1)$ & $24.5(3.2-97.6)$ & 0.004 & $<0.001$ \\
\hline Ketoacidosis (\%) & 4.3 & 19.1 & 0.13 & 0.09 \\
\hline $\mathrm{pH}$, median (range) & $7.40(7.27-7.51)$ & $7.38(6.80-7.54)$ & 0.001 & 0.007 \\
\hline$\beta$-Hydroxybutyrate (mmol/l), median (range) & $0.3(0-6.0)$ & $1.8(0-20.1)$ & 0.004 & $<0.001$ \\
\hline Impaired consciousness (\%) & 0.0 & 5.1 & 0.62 & 1.00 \\
\hline Duration of symptoms (days), median (range) & $21.5(0-61)$ & $9.0(0-377)$ & 0.03 & 0.65 \\
\hline Weight loss (kg), median (range) & $1.1(0-5.0)$ & $1.4(0-20.0)$ & 0.50 & 0.09 \\
\hline \multicolumn{5}{|l|}{ Autoantibodies } \\
\hline ICA (\%) & 78.3 & 93.4 & 0.01 & 0.02 \\
\hline ICA (JDFU), median (range) & $40(4-640)$ & $40(2.5-39935)$ & 0.97 & 1.00 \\
\hline IAA (\%) & 30.4 & 44.4 & 0.21 & 0.40 \\
\hline IAA (RU), median (range) & $7.9(4.7-22.3)$ & $10.3(2.9-309.3)$ & 0.35 & 0.77 \\
\hline IA-2A (\%) & 60.9 & 76.0 & 0.14 & 0.10 \\
\hline IA-2A (RU), median (range) & $74.5(0.9-193.5)$ & $101.8(0.9-553.3)$ & 0.39 & 0.68 \\
\hline GADA (\%) & 65.2 & 66.9 & 1.00 & 0.86 \\
\hline GADA (RU), median (range) & $81.6(6.5-419.6)$ & $39.4(5.4-812.4)$ & 0.13 & $<0.001$ \\
\hline Number of positive antibodies, median (mean) & $2(2.35)$ & $3(2.81)$ & 0.14 & 0.10 \\
\hline \multicolumn{5}{|l|}{ Genetics } \\
\hline DR3-DQ2/DR4-DQ8 (\%) & 13.0 & 22.0 & 0.33 & 0.33 \\
\hline DR3-DQ2/ $x^{\mathrm{b}}(\%)$ & 26.1 & 16.2 & 0.25 & 0.19 \\
\hline DR4-DQ8/yc (\%) & 47.8 & 46.6 & 1.00 & 0.93 \\
\hline$x^{b} / y^{c}$ & 13.0 & 15.2 & 1.00 & 0.73 \\
\hline DR4-DQ8 positive (\%) & 60.9 & 68.7 & 0.50 & 0.43 \\
\hline DR3-DQ2 positive (\%) & 39.1 & 38.1 & 1.00 & 0.86 \\
\hline
\end{tabular}

${ }^{\mathrm{a}}$ The results are adjusted for the difference in age at diagnosis.

${ }^{\mathrm{b}} x \neq \mathrm{DR} 4-\mathrm{DQ8}$.

${ }^{c} y \neq$ DR3-DQ2.

families, i.e. the number of children in the family was higher $(P<0.05)$ in most comparisons. The number of children in the family did not significantly affect the variables tested, however, and thus was not included in the analysis as a confounding factor.

Familial T1D of these children has been described earlier (29); $21.8 \%$ had a positive family history of T1D among the extended family. The frequency of familial T1D did not differ according to the positive or negative history of other AIDs in the index child (Table 1) or in the extended family ( 23.8 vs $21.0 \%, P=0.25$ ).

\section{Autoantibodies}

After adjustment for the difference in age at diagnosis, the children with a known additional AID at the presentation of T1D were less often positive for ICAs and had higher levels of GADAs (Table 1). The children with relatives affected by AIDs had higher levels of ICAs and IA-2A than those with no family history of AIDs, whereas no differences were observed in the autoantibody profile in the children from autoimmune families (Table 2).
Higher levels of ICAs were observed in the children with rheumatoid diseases (44 vs 40 JDF units, $P=0.001)$ or AIT among relatives (44 vs $40 \mathrm{JDF}$ units, $P=0.04)$. The children with rheumatoid diseases among relatives had, in addition, higher levels of IA-2A (109.7 vs 99.5 RU, $P=0.006)$. The children with or without a positive family history of $\mathrm{CD}$ did not differ in terms of autoantibodies.

\section{Genetics}

HLA risk haplotypes or genotypes of the 23 children with another known AID at diagnosis did not differ from those of the subjects with T1D only (Table 1). HLA genetic profile was similar in the children with or without a positive family history of AIDs and those from autoimmune families (Table 2).

The children with relatives affected by AIT or rheumatoid diseases in the extended family did not differ from those without a family history of AIDs in terms of HLA genetics. The children with a positive family history of $\mathrm{CD}$, however, carried more often the DR3-DQ2 haplotype $(66.0$ vs $38.9 \%, P<0.001)$, 
Table 2 Metabolic, immunological, and genetic markers in index cases with first- and/or second-degree relatives affected by autoimmune diseases (AIDs, Group la) and in index cases from autoimmune families (greater than three AID diagnoses and/or greater than two different AIDs in the extended family, Group lb) compared with the children with no family history of AIDs (Group II). Bold P values refer to significant differences.

\begin{tabular}{|c|c|c|c|c|c|}
\hline & $\begin{array}{l}\text { Group la: children } \\
\text { with AIDs in the } \\
\text { extended family } \\
\quad(n=356)\end{array}$ & $\begin{array}{l}\text { Group lb: children } \\
\text { from autoimmune } \\
\text { families }(n=150)\end{array}$ & $\begin{array}{l}\text { Group II: children } \\
\text { with no additional } \\
\text { autoimmunity in } \\
\text { the extended } \\
\text { family }(n=807)\end{array}$ & $\begin{array}{l}\text { Group } \\
\text { la vs II: } \\
P \text { value }\end{array}$ & $\begin{array}{l}\text { Group } \\
\text { Ib vs II: } \\
P \text { value }\end{array}$ \\
\hline \multicolumn{6}{|l|}{ Demographics } \\
\hline Sex: male (\%) & 58.7 & 57.3 & 55.6 & 0.36 & 0.77 \\
\hline Age of father at diagnosis (years), median & 40.5 & 41.3 & 39.7 & 0.23 & 0.005 \\
\hline Age of mother at diagnosis (years), mean & 38.2 & 39.0 & 37.8 & 0.30 & 0.02 \\
\hline Number of children in the family, median (mean) & $2(2.42)$ & $2(2.73)$ & $2(2.32)$ & 0.05 & 0.009 \\
\hline \multicolumn{6}{|l|}{ Metabolic decompensation at diagnosis } \\
\hline Plasma glucose (mmol/l), median (range) & $25.1(3.2-64.6)$ & $22.9(3.2-63.7)$ & $24.8(4.5-92.7)$ & 0.64 & 0.003 \\
\hline Ketoacidosis (\%) & 19.4 & 14.2 & 22.3 & 0.31 & 0.04 \\
\hline $\mathrm{pH}$, median (range) & $7.38(6.88-7.52)$ & $7.39(6.98-7.54)$ & $7.37(6.87-7.52)$ & 0.11 & $<0.001$ \\
\hline$\beta$-Hydroxybutyrate (mmol/l), median (range) & $1.9(0-15.1)$ & $1.0(0-17.4)$ & $2.3(0-13.2)$ & 0.34 & $<0.001$ \\
\hline Duration of symptoms (days), median (range) & $10.5(0-377)$ & $8.5(0-143)$ & $10(0-314)$ & 0.18 & 0.61 \\
\hline Weight loss $(\mathrm{kg})$, median (range) & $1.5(0-20.0)$ & $1.5(0-12.0)$ & $1.5(0-17.0)$ & 0.66 & 0.14 \\
\hline \multicolumn{6}{|l|}{ Autoantibodies } \\
\hline ICA (\%) & 95.1 & 89.0 & 93.2 & 0.30 & 0.11 \\
\hline ICA (JDFU), median (range) & $44(2.5-640)$ & $44(3-640)$ & $40(3-39935)$ & 0.003 & 0.39 \\
\hline IAA (\%) & 46.1 & 38.6 & 43.5 & 0.46 & 0.32 \\
\hline IAA (RU), median (range) & $10.3(2.9-171.2)$ & $11.1(2.9-198.5)$ & $10.0(2.9-309.3)$ & 0.59 & 0.29 \\
\hline IA-2A (\%) & 79.1 & 73.1 & 75.0 & 0.16 & 0.71 \\
\hline IA-2A (RU), median (range) & $105.7(0.9-553.3)$ & $102.5(0.9-553.3)$ & $99.5(0.9-501.0)$ & 0.05 & 0.18 \\
\hline GADA (\%) & 68.1 & 70.3 & 66.7 & 0.68 & 0.44 \\
\hline GADA (RU), median (range) & $41.3(5.5-501.9)$ & $45.2(6.0-341.1)$ & $41.0(5.6-812.4)$ & 0.82 & 0.77 \\
\hline Number of positive antibodies, median (mean) & $3(2.88)$ & $3(2.71)$ & $3(2.78)$ & 0.30 & 0.49 \\
\hline \multicolumn{6}{|l|}{ Genetics } \\
\hline DR3-DQ2/DR4-DQ8 (\%) & 21.7 & 20.9 & 21.3 & 0.93 & 1.00 \\
\hline DR3-DQ2/ $x^{\mathrm{a}}(\%)$ & 15.1 & 17.6 & 17.8 & 0.30 & 1.00 \\
\hline DR4-DQ8/y $(\%)$ & 46.9 & 50.7 & 44.9 & 0.59 & 0.23 \\
\hline$x^{\mathrm{a} / y^{\mathrm{b}}}$ & 16.3 & 10.8 & 15.9 & 0.96 & 0.14 \\
\hline
\end{tabular}

${ }^{\mathrm{a}} x \neq \mathrm{DR} 4-\mathrm{DQ} 8$.

${ }^{\mathrm{b}} y \neq \mathrm{DR} 3-\mathrm{DQ} 2$.

the DR3-DQ2/DR4-DQ8 genotype (35.8 vs $21.3 \%$, $P=0.02)$, and the DR3-DQ2/nonDR4-DQ8 genotype (30.2 vs $17.8 \%, P=0.04$ ). The frequencies of nonDR3-DQ2/DR4-DQ8 (30.2 vs $44.9 \%, P=0.05)$ and nonDR3-DQ2/nonDR4-DQ8 (3.8 vs $15.9 \%$, $P=0.03)$ genotypes were reduced.

\section{Metabolic decompensation at diagnosis}

After adjustment for the age at diagnosis, the children with another AID already at the presentation of T1D had lower plasma glucose levels, higher $\mathrm{pH}$ and lower $\beta$-hydroxybutyrate levels (Table 1). Similarly, the children from autoimmune families had lower plasma glucose level and were less acidotic, whereas those with or without a positive family history of other AIDs did not differ (Table 2).

A positive family history of AIT or rheumatoid diseases did not reveal any differences in the markers of metabolic decompensation of the index child.
The children who had relatives with CD had symptoms for a longer duration than those without any family history of AIDs (15 vs 10 days, $P=0.02$ ).

\section{Discussion}

In this cross-sectional population-based study, we characterized the family history of AIDs in Finnish families with a diabetic child and looked for differences in diabetes phenotype and genotype depending on such a history. As the HLA-DR3-DQ2 haplotype is a risk haplotype for AIDs $(20,22,25)$, especially for CD (11, $19,21,23,24,25)$, we expected it to be more prevalent among the children with a positive family history of AIDs. Such an increase in the frequency of the haplotype was not observed, in general, but the haplotype was strongly associated with a positive family history of CD. In addition, we postulated that a positive family history of AIDs would result in a stronger 
humoral immune response to $\beta$-cell antigens. A broad activation of autoimmune reactions reflected by multiple different AIDs in the family could translate into a broad activation of immune reactions against T1D-related autoantigens in the index child. We did observe higher ICA and/or IA-2A titers in the children with a positive family history of AIDs, but no differences in the frequencies of autoantibodies were evident. In summary, although we found some differences in $\beta$-cell autoimmunity in the children with a positive family history of AIDs, the differences were modest. To further characterize the effects of a positive family history of AIDs, we grouped the index children into autoimmune families, in which autoimmunity was truly clustered, and accordingly, differences in pathogenetic mechanisms should be evident. The only significant difference observed, however, was the milder metabolic decompensation at diagnosis among the children from autoimmune families, which is probably due to the effect of familial diabetes and the earlier recognition of symptoms in such families (29). These findings do not consistently support the hypothesis of different pathogenetic mechanisms of diabetes operating in families with clustered autoimmunity.

Our dataset included only 23 children (1.5\%) with another AID already known at T1D diagnosis. This is in keeping with previous studies in that additional autoimmunity is generally diagnosed after the clinical presentation of T1D $(8,9,14)$. We did not screen for organ-specific autoantibodies such as tissue transglutaminase, 21-hydroxylase, and thyroid autoantibodies and were accordingly not able to diagnose subclinical conditions. This makes our prevalence of additional autoimmunity lower than that reported previously for children at diagnosis $(8,10)$. The children with multiple AIDs tended to be older at diagnosis, and they had somewhat milder metabolic decompensation. The duration of symptoms did not differ, however, after adjustment for age at diagnosis. These findings suggest a milder clinical manifestation of T1D in pediatric patients with a known additional AID. This seems to be not due to earlier diagnosis, but rather suggests a slower diabetic disease process. Accordingly, some differences in $\beta$-cell autoimmunity were also observed; these children had ICAs less frequently and had higher levels of GADAs after adjustment for age at diagnosis. This is in line with GADAs being associated with a general propensity to develop autoimmunity $(14,20,22,26)$. However, no inverse relationship between IA-2A and additional autoimmunity (20) or differences in genetics were observed possibly due to the small number of cases.

One-third of the index children had at least one extended family member affected by an AID other than T1D. In previous reports, this proportion has ranged from 20 to $70 \%(1,2,3,8,18,20,36)$. These studies, however, vary in terms of T1D duration, possible screening of family members for autoantibodies, and the categories of relatives included in the analysis. The index cases had more often second-degree relatives than first-degree ones affected by AIDs (Fig. 2). This can be readily explained by older age and thus longer follow-up of second-degree relatives. As the total number of second-degree relatives is unknown, we are unable to report the actual prevalence of AIDs in this group. Families with a positive family history of AIDs had a higher number of children and the parents were older at the diagnosis of the index case, reflecting that a larger family size and a longer observation time increase the chances for AID diagnoses. Interestingly, parity has been identified as a risk factor for many AIDs (37), and this could contribute to the increased prevalence of AIDs in larger families.

In accordance with previous findings, mothers were more often affected by an AID other than T1D compared with fathers $(16,18,38)$. Similarly, maternal grandparents and maternal relatives, in general, were affected by AIDs more often than paternal counterparts. This could reflect the increased genetic risk of autoimmunity in the relatives of mothers or a recollection bias in the form of mothers being more aware than fathers of the diseases diagnosed in their relatives. Interestingly, in the same dataset, such a difference was not observed for T1D; it was reported equally often in maternal $(6.5 \%)$ and paternal $(6.0 \%)$ second-degree relatives, but was more common in fathers $(6.2 \%)$ than in mothers (3.2\%) (29). This emphasizes the differential sex distributions and possible sex-dependent inheritance patterns in T1D and other AIDs. Despite these differences, based on the general clustering of autoimmunity, an increased prevalence of T1D could be expected in families with multiple AID diagnoses. However, the prevalence of familial T1D did not differ between the children from families with a positive or negative family history of other AIDs.

The asset of our study is that the subjects were derived from a nationwide register, which includes more than $90 \%$ of pediatric patients with T1D diagnosed in a country with the highest incidence of T1D globally. This high level of ascertainment and the large sample were made possible by relying on the information provided by the questionnaires on the extended family history of AIDs. The questionnaires were completed with the help of health care professionals, and the intention was to ensure the autoimmune origin of the reported diseases. Despite the efforts, this cannot be guaranteed, as the family members were not systematically contacted to confirm the diagnosis. If the questions about AIDs in the questionnaires were left unanswered, the family was counted as not having any family members affected by AIDs. Accordingly, our results can be expected to be conservative and to some extent underestimate the proportion of children with AIDs in their relatives. In addition, only clinically manifested autoimmunity was included in our questionnaire-based study, leaving subclinical conditions undetected. Consequently, the ascertainment of AIDs is the major limitation of our study as strict ascertainment was not possible in such a large dataset. 
This study did not provide consistent support for the differential pathogenetic mechanisms of T1D in families with clustered autoimmunity; enrichment of HLA class II risk haplotypes was not observed, and only modest differences in autoantibody profile were apparent. Clustered autoimmunity in the extended family was, however, a fairly common phenomenon with one-third of the children having a first- or second-degree relative diagnosed with an AID. Reasons for this clustering still remain unclear and call for further studies.

\section{Declaration of interest}

The authors declare that there is no conflict of interest that could be perceived as prejudicing the impartiality of the research reported.

\section{Funding}

This study was supported by the Academy of Finland (Centre of Excellence in Molecular Systems Immunology and Physiology Research 2012-2017, Decision no. 250114), the Sigrid Jusélius Foundation, the Novo Nordisk Foundation, the Liv and Hälsa Fund, the Finnish Medical Foundation, and the National Graduate School of Clinical Investigation.

\section{Author contribution statement}

A Parkkola analyzed the data, wrote the first version of the manuscript, and edited the manuscript; T Härkönen was in charge of the autoantibody laboratory, reviewed the manuscript, and contributed to the discussion; J Ilonen was responsible for the HLA genotyping, reviewed the manuscript, and contributed to the discussion; S J Ryhänen reviewed the manuscript and contributed to the discussion; and M Knip planned the study, contributed to the discussion, and reviewed the manuscript. The participants of the Finnish Pediatric Diabetes Register were involved in the planning of the study design and collection of data.

\section{Acknowledgements}

This study has been presented at the 47th EASD Annual Meeting 2011 and published as an abstract in Diabetologia $\mathbf{5 4}$ (Suppl 1) S19. 2011. We thank Matti Koski and Sirpa Nolvi from the University of Helsinki for their technical assistance with the Register. The following investigators belong to the Finnish Pediatric Diabetes Register and Biobank: Principal Investigator: M Knip (Children’s Hospital, Helsinki University Central Hospital). Steering Committee: Per-Henrik Groop (Folkhälsan Research Center), J Ilonen (Immunogenetics Laboratory, University of Turku), Anneli Lappi (Children's Hospital, Helsinki University Central Hospital), Timo Otonkoski (Children's Hospital, Helsinki University Central Hospital), Marja-Terrtu Saha (Department of Pediatrics, Tampere University Hospital), Olli Simell (Chair, Department of Pediatrics, Turku University Central Hospital), Timo Talvitie (Department of Pediatrics, South Ostrobothnia Central Hospital), Outi Vaarala (Department of Vaccination and Immune Protection, National Institute for Health and Welfare), and Riitta Veijola (Department of Pediatrics, Oulu University Hospital). Locally responsible investigators: Henrikka Aito (Department of Pediatrics, Porvoo Hospital), Jonas Bondestam (Department of Pediatrics, Lohja Hospital), Thomas Dahllund (Department of Pediatrics, Västra Nyland Hospital), Johanna Granvik (Department of Pediatrics, Jakobstad Hospital), Maarit Haapalehto-Ikonen (Department of Pediatrics, Rauma Hospital), Anu-Maaria Hämäläinen (Department of Pediatrics, Jorvi Hospital), Hanna Huopio (Department of Pediatrics, Kuopio University Hospital), Christian Johansson (Department of Pediatrics, Åland Central Hospital), Anne Kinnala (Department of Pediatrics, Salo
Hospital), Jussi Korhonen (Department of Pediatrics, North Karelia Central Hospital), Maarit Korteniemi (Department of Pediatrics, Central Hospital of Lapland), Pentti Lautala (Department of Pediatrics, Päijät-Häme Central Hospital), Kaija Lindström (Department of Pediatrics, Hyvinkää Hospital), Päivi Miettinen (Children's Hospital, Helsinki University Central Hospital), Taina Mustila (Department of Pediatrics, Vaasa Central Hospital), Anja Nuuja (Department of Pediatrics, Central Hospital of Central Finland), Päivi Nykänen (Department of Pediatrics, Mikkeli Central Hospital), Jussi Ojanperä (Department of Pediatrics, Central Ostrobothnia Central Hospital), Anne-Putto-Laurila (Department of Pediatrics, Turku University Central Hospital), Marja-Terttu Saha (Department of Pediatrics, Tampere University Hospital), Juhani Sankila (Department of Pediatrics, Savonlinna Central Hospital), Anne-Maarit Suomi (Department of Pediatrics, South Ostrobothnia Central Hospital), Sirpa Tenhola (Department of Pediatrics, Kymenlaakso Central Hospital), Pentti Varimo (Department of Pediatrics, Kainuu Central Hospital), Riitta Veijola (Department of Pediatrics, Oulu University Hospital), Ritva Virransalo (Department of Pediatrics, South Karelia Central Hospital), Pentti Vuolukka (Department of Pediatrics, Länsi-Pohja Central Hospital), Paavo Korpela (Department of Pediatrics, KantaHäme Central Hospital), and Samuli Ylitalo (Department of Pediatrics, Satakunta Central Hospital).

\section{References}

1 Alhonen S, Korhonen S, Tapanainen P, Knip M \& Veijola R. Extended family history of diabetes and autoimmune diseases in children with and without type 1 diabetes. Diabetes Care 201134 115-117. (doi:10.2337/dc10-1091)

2 Betterle C, Zanette F, Pedini B, Presotto F, Rapp LB, Monciotti CM \& Rigon F. Clinical and subclinical organ-specific autoimmune manifestations in type 1 (insulin-dependent) diabetic patients and their first-degree relatives. Diabetologia 198426 431-436. (doi:10.1007/BF00262215)

3 Hanukoglu A, Mizrachi A, Dalal I, Admoni O, Rakover Y, Bistritzer Z, Levine A, Somekh E, Lehmann D, Tuval M et al. Extrapancreatic autoimmune manifestations in type 1 diabetes patients and their first-degree relatives: a multicenter study. Diabetes Care 200326 1235-1240. (doi:10.2337/diacare.26.4.1235)

4 Hemminki K, Li X, Sundquist J \& Sundquist K. Familial association between type 1 diabetes and other autoimmune and related diseases. Diabetologia 200952 1820-1828. (doi:10.1007/s00125-0091427-3)

5 Warncke K, Frohlich-Reiterer EE, Thon A, Hofer SE, Wiemann D, Holl RW, DPV Initiative of the German Working Group for Pediatric Diabetology \& German BMBF Competence Network for Diabetes Mellitus . Polyendocrinopathy in children, adolescents, and young adults with type 1 diabetes: a multicenter analysis of 28,671 patients from the German/Austrian DPV-Wiss database. Diabetes Care 201033 2010-2012. (doi:10.2337/dc10-0404)

6 Marrosu MG, Cocco E, Lai M, Spinicci G, Pischedda MP \& Contu P. Patients with multiple sclerosis and risk of type 1 diabetes mellitus in Sardinia, Italy: a cohort study. Lancet 2002359 1461-1465. (doi:10.1016/S0140-6736(02)08431-3)

7 Nielsen NM, Westergaard T, Frisch M, Rostgaard K, Wohlfahrt J, Koch-Henriksen N, Melbye M \& Hjalgrim H. Type 1 diabetes and multiple sclerosis: a Danish population-based cohort study. Archives of Neurology 200663 1001-1004. (doi:10.1001/archneur.63. 7.1001)

8 Lebenthal Y, Yackobovitch-Gavan M, de Vries L, Phillip M \& Lazar L. Coexistent autoimmunity in familial type 1 diabetes: increased susceptibility in sib-pairs? Hormone Research in Paediatrics 201175 284-290. (doi:10.1159/000322936)

9 Kordonouri O, Hartmann R, Deiss D, Wilms M \& GrütersKieslich A. Natural course of autoimmune thyroiditis in type 1 diabetes: association with gender, age, diabetes duration, and puberty. Archives of Disease in Childhood 20059 411-414. (doi:10.1136/adc.2004.056424) 
10 Triolo TM, Armstrong TK, McFann K, Yu L, Rewers MJ, Klingensmith GJ, Eisenbarth GS \& Barker JM. Additional autoimmune disease found in $33 \%$ of patients at type 1 diabetes onset. Diabetes Care 201134 1211-1213. (doi:10.2337/dc10-1756)

11 Saukkonen T, Savilahti E, Reijonen H, Ilonen J, Tuomilehto-Wolf E \& Akerblom HK. Coeliac disease: frequent occurrence after clinical onset of insulin-dependent diabetes mellitus. Childhood diabetes in Finland study group. Diabetic Medicine 199613 464-470. (doi:10.1002/(SICI)1096-9136(199605)13:5<464:: AID-DIA101>3.0.CO;2-R)

12 Larsson K, Carlsson A, Cederwall E, Jonsson B, Neiderud J, Jonsson B, Lernmark A, Ivarsson SA \& Skane Study Group. Annual screening detects celiac disease in children with type 1 diabetes. Pediatric Diabetes 20089 354-359. (doi:10.1111/ j.1399-5448.2008.00367.x)

13 Glastras SJ, Craig ME, Verge CF, Chan AK, Cusumano JM \& Donaghue KC. The role of autoimmunity at diagnosis of type 1 diabetes in the development of thyroid and celiac disease and microvascular complications. Diabetes Care 200528 2170-2175. (doi:10.2337/diacare.28.9.2170)

14 Kordonouri O, Charpentier N \& Hartmann R. GADA positivity at onset of type 1 diabetes is a risk factor for the development of autoimmune thyroiditis. Pediatric Diabetes 201112 31-33. (doi:10.1111/j.1399-5448.2010.00666.x)

15 Jaeger C, Hatziagelaki E, Petzoldt R \& Bretzel RG. Comparative analysis of organ-specific autoantibodies and celiac disease - associated antibodies in type 1 diabetic patients, their first-degree relatives, and healthy control subjects. Diabetes Care 200124 27-32. (doi:10.2337/diacare.24.1.27)

16 Tait KF, Marshall T, Berman J, Carr-Smith J, Rowe B, Todd JA, Bain SC, Barnett AH \& Gough SC. Clustering of autoimmune disease in parents of siblings from the type 1 diabetes Warren repository. Diabetic Medicine 200421 358-362. (doi:10.1111/ j.1464-5491.2004.01162.x)

17 De Block CE, De Leeuw IH, Decochez K, Winnock F, Van Autreve J, Van Campenhout CM, Martin M, Gorus FK \& Belgian Diabetes R. The presence of thyrogastric antibodies in first degree relatives of type 1 diabetic patients is associated with age and proband antibody status. Journal of Clinical Endocrinology and Metabolism 200186 4358-4363. (doi:10.1210/jc.86.9.4358)

18 Anaya JM, Castiblanco J, Tobon GJ, Garcia J, Abad V, Cuervo H, Velasquez A, Angel ID, Vega P \& Arango A. Familial clustering of autoimmune diseases in patients with type 1 diabetes mellitus. Journal of Autoimmunity 200626 208-214. (doi:10.1016/j.jaut. 2006.01.001)

19 Dezsofi A, Szebeni B, Hermann CS, Kapitany A, Veres G, Sipka S, Korner A, Madacsy L, Korponay-Szabo I, Rajczy K et al. Frequencies of genetic polymorphisms of TLR4 and CD14 and of HLA-DQ genotypes in children with celiac disease, type 1 diabetes mellitus, or both. Journal of Pediatric Gastroenterology and Nutrition 200847 283-287. (doi:10.1097/MPG.0b013e31816de885)

20 Wagner AM, Santana A, Hernndez M, Wiebe JC, Novoa J, Mauricio D \& T1DGC6. Predictors of associated autoimmune diseases in families with type 1 diabetes: results from the Type 1 Diabetes Genetics Consortium. Diabetes/Metabolism Research and Reviews 201127 493-498. (doi:10.1002/dmrr.1189)

21 Barker JM, Yu J, Yu L, Wang J, Miao D, Bao F, Hoffenberg E, Nelson JC, Gottlieb PA, Rewers M et al. Autoantibody "subspecificity" in type 1 diabetes: risk for organ-specific autoimmunity clusters in distinct groups. Diabetes Care 200528 850-855. (doi:10.2337/diacare.28.4.850)

22 De Block CE, De Leeuw IH, Vertommen JJ, Rooman RP, Du Caju MV, Van Campenhout CM, Weyler JJ, Winnock F, Van Autreve J, Gorus FK et al. $\beta$-Cell, thyroid, gastric, adrenal and coeliac autoimmunity and HLA-DQ types in type 1 diabetes. Clinical and Experimental Immunology $2001 \mathbf{1 2 6}$ 236-241. (doi:10.1046/j.1365-2249.2001.01668.x)

23 Hummel M, Bonifacio E, Stern M, Dittler J, Schimmel A \& Ziegler AG. Development of celiac disease-associated antibodies in offspring of parents with type I diabetes. Diabetologia 200043 1005-1011. (doi:10.1007/s001250051483)
24 Sumnik Z, Cinek O, Bratanic N, Kordonouri O, Kulich M, Roszai B, Arato A, Lebl J, Soltesz G, Danne T et al. Risk of celiac disease in children with type 1 diabetes is modified by positivity for HLA-DQB1*02-DQA1*05 and TNF -308A. Diabetes Care 200629 858-863. (doi:10.2337/diacare.29.04.06.dc05-1923)

25 Yu L, Brewer GS, Gates S, Wu A, Wang T, Babu SR, Gottlieb PA, Freed BM, Noble J, Erlich HA et al. DRB1*04 and DQ alleles: expression of 21-hydroxylase autoantibodies and risk of progression to Addison's disease. Journal of Clinical Endocrinology and Metabolism 199984 328-335. (doi:10.1210/jc.84.1.328)

26 Karavanaki K, Kakleas K, Paschali E, Kefalas N, Konstantopoulos I, Petrou V, Kanariou M \& Karayianni C. Screening for associated autoimmunity in children and adolescents with type 1 diabetes mellitus (T1DM). Hormone Research 200971 201-206. (doi:10.1159/000201108)

27 Makinen A, Harkonen T, Ilonen J, Knip M \& Finnish Pediatric Diabetes Register. Characterization of the humoral immune response to islet antigen 2 in children with newly diagnosed type 1 diabetes. European Journal of Endocrinology 2008159 19-26. (doi:10.1530/EJE-07-0853)

28 Hekkala A, Reunanen A, Koski M, Knip M, Veijola R \& Finnish Pediatric Diabetes Register. Age-related differences in the frequency of ketoacidosis at diagnosis of type 1 diabetes in children and adolescents. Diabetes Care 201033 1500-1502. (doi:10.2337/dc09-2344)

29 Parkkola A, Härkönen T, Ryhänen SJ, Ilonen J, Knip M \& Finnish Pediatric Diabetes Register. Extended family history of type 1 diabetes and phenotype and genotype of newly diagnosed children. Diabetes Care 201336 348-354. (doi:10.2337/dc12-0445)

30 Hermann R, Turpeinen H, Laine AP, Veijola R, Knip M, Simell O, Sipila I, Akerblom HK \& Ilonen J. HLA DR-DQ-encoded genetic determinants of childhood-onset type 1 diabetes in Finland: an analysis of 622 nuclear families. Tissue Antigens 200362 162-169. (doi:10.1034/j.1399-0039.2003.00071.x)

31 Ronkainen MS, Hamalainen AM, Koskela P, Akerblom HK, Knip M \& Finnish Trigr Study Group. Pregnancy induces nonimmunoglobulin insulin-binding activity in both maternal and cord blood serum. Clinical and Experimental Immunology 2001124 190-196. (doi:10.1046/j.1365-2249.2001.01506.x)

32 Savola K, Sabbah E, Kulmala P, Vahasalo P, Ilonen J \& Knip M. Autoantibodies associated with type I diabetes mellitus persist after diagnosis in children. Diabetologia 199841 1293-1297. (doi:10.1007/s001250051067)

33 Savola K, Bonifacio E, Sabbah E, Kulmala P, Vahasalo P, Karjalainen J, Tuomilehto-Wolf E, Merilainen J, Akerblom HK \& Knip M. IA-2 antibodies - a sensitive marker of IDDM with clinical onset in childhood and adolescence. Childhood Diabetes in Finland Study Group. Diabetologia 199841 424-429. (doi:10.1007/s001250050925)

34 Bottazzo GF, Florin-Christensen A \& Doniach D. Islet-cell antibodies in diabetes mellitus with autoimmune polyendocrine deficiencies. Lancet 19742 1279-1283. (doi:10.1016/S01406736(74)90140-8)

35 R Development Core Team. R: a language and environment for statistical computing. In R Foundation for Statistical Computing. Vienna, Austria: ISBN 3-900051-07-0 (http://www.R-project.org/), 2010.

36 Sipetic S, Vlajinac H, Kocev N, Marinkovic J, Radmanovic S \& Denic L. Family history and risk of type 1 diabetes mellitus. Acta Diabetologia 200239 111-115. (doi:10.1007/s005920200028)

37 Jørgensen KT, Pedersen BV, Nielsen NM, Jacobsen S \& Frisch M. Childbirths and risk of female predominant and other autoimmune diseases in a population-based Danish cohort. Journal of Autoimmunity 201238 J81-J87. (doi:10.1016/j.jaut.2011.06.004)

38 Zandman-Goddard G, Peeva E \& Shoenfeld Y. Gender and autoimmunity. Autoimmunity Reviews 20076 366-372. (doi:10.1016/ j.autrev.2006.10.001)

Received 29 January 2013

Revised version received 23 April 2013

Accepted 22 May 2013 